Diet of spotted hyaenas

\title{
Anthropogenic influences on spotted hyaena diet in the Kruger National Park, South Africa
}

\author{
L.E. Belton' ${ }^{1}$ E.Z. Cameron ${ }^{1,2,3}$, F. Dalerum ${ }^{1,4,5}$ * \\ 1 Mammal Research Institute, Department of Zoology and Entomology, University of Pretoria, \\ Pretoria, South Africa \\ 2 School of Biological Sciences, University of Canterbury, Christchurch, New Zealand \\ 3 School of Biological Sciences, University of Tasmania, Hobart, Australia \\ 4 Research Unit of Biodiversity (UO-CSIC-PA), University of Oviedo, Mieres Campus, 33600 \\ Mieres, Spain \\ 5 Department of Zoology, Stockholm University, 106 91, Stockholm, Sweden
}

\section{Correspondence}

*Fredrik Dalerum, Research Unit of Biodiversity (UO, GA, CSIC), University of Oviedo, Mieres, 33600 Mieres, Asturias, Spain

Email: dalerumjohan@,uniovi.es

\begin{abstract}
Rapid urban expansion has led to an increase in carnivores that live close to human dominated environments. Some carnivore species have successfully adapted to these novel conditions and taken advantage of opportunities associated with human habitation. Whilst many studies have compared carnivores living in protected areas to those in an urban setting, few have looked at the relationships between carnivores and human habitation within protected areas. In this study we examined the effects of human habitation on the diet of spotted hyaenas (Crocuta crocuta) in the Kruger National Park (KNP), South Africa. Our results suggested a limited effect of anthropogenic resources on spotted hyaena diet in the KNP. We found neither temporal nor spatial variation in the amount of, nor types of, anthropogenic material in spotted hyaena scats, despite observations of more road side litter close to large anthropogenic sites. We therefore suggest that anthropogenic resources may not have been utilized completely according to abundance. We encourage further research evaluating potential secondary effects of human activity and infrastructure on spotted hyaena diet, and also stable isotope approaches that may provide further insights into the importance of anthropogenic food for spotted hyaenas inside the KNP.
\end{abstract}

Key words

Crocuta crocuta, Carnivora, anthropogenic resources, protected areas

Mammal Research, In Press 


\section{Introduction}

Human population growth is often correlated with the decline, or local extinction, of carnivore populations (Woodroffe 2000). The rapidly expanding extent of urban landscapes creates both biotic and abiotic challenges that negatively impact carnivores (Š́lek et al. 2015). Carnivores are considered particularly sensitive to human population growth and urbanisation due to persecution, large home range requirements and slow population growth (Woodroffe 2000). However, urban landscapes also offer alternative resources, such as access to predictable food, water and shelter (Bateman and Fleming 2012; Laver 2013). Consequently, some carnivore species not only co-exist with humans, but thrive in urban environments (Bateman and Fleming 2012).

Carnivore synanthropy (wild animals gaining benefit from living in close association with humans) has been recorded across six of the seven continents (Newsome et al. 2015). Species recorded to live in close association with humans range in size from the mongooses (Herpestidae) (Laver 2013), to bears (Ursidae) (Beckmann and Berger 2003). The often predictable nature of the anthropogenic food sources makes urban areas a reliable alternative to the often seasonal changes of natural resources (Widdows and Downs 2015). Therefore, urban environments can be regarded as a distinct wildlife habitat (Š́lek et al. 2015), and urban ecology is subsequently expanding rapidly as a research focus (Magle et al. 2012).

The effects of anthropogenic food availability on overall diet have been studied in a number of species. Throughout this manuscript, we will use the term 'anthropogenic food' for organic matter that has been discarded by humans and is available for exploitation by carnivores and 'anthropogenic material' for man-made matter (e.g. plastic or paper) that is found in the scat of animals utilising anthropogenic food. A seasonal change in anthropogenic food use was observed in coyotes, with a greater use during the dispersal season and by transient animals (Grigione et al. 2011; Lukasik and Alexander 2012). A preference for anthropogenic food during the winter months has also been observed in large spotted genets (Genetta tigrina) (Widdows and Downs 2015). Reductions in natural resources or the ability to procure them has been suggested as the cause of a switch to anthropogenic food in red (Vulpes vulpes) and Arctic foxes (Vulpes lagopus) (Savory et al. 2014), as well as in spotted hyenas (Crocuta crocuta) (Kolowski and Holekamp 2008). These findings indicate that anthropogenic food may be less preferred to natural foods, and only utilised by animals in poor health that need food that is easy to procure (Murray et al. 2015), or by animals that experience periods of food scarcity.

Different types and levels of urbanisation will produce contrasting challenges and opportunities for carnivores. Whilst the majority of the scientific studies have focussed on carnivores living in nonprotected environments, pockets of high human presence also occur inside protected areas (e.g. Gilchrist and Otali 2002; Quinn and Whisson 2005). Many of the features associated with different anthropogenic zones therefore also occur in protected areas, with anthropogenic food provided as a predictable but patchy resource. However, despite the obvious conservation and management implications of the utilization of anthropogenic food by large predators inside conservation areas, studies on anthropogenic food use within protected areas is scarce compared to data focusing on urban and suburban landscapes.

The spotted hyaena is a large carnivore that lives in social groups known as clans, consisting of related females and their offspring and unrelated adult males. Male offspring usually disperse at maturity (Kruuk 1972). A strict matrilineal social structure is maintained through social interactions (Frank 1986). The range of the spotted hyaena covers much of sub Saharan Africa, from the 
Kalahari Desert (Mills 1984), to a peri-urban existence in Ethiopia (Abay et al. 2010), although distribution is patchy (IUCN 2015). Spotted hyaenas exhibit high levels of behavioural plasticity, including dietary plasticity (Hayward 2006; Holekamp and Dloniak 2010). Once considered mere scavengers, spotted hyaenas are successful hunters, capable of hunting adult Cape buffalo (Syncerus caffer) (Cooper et al. 1999) and gemsbok (Oryx gazella) (Trinkel 2009). Other dietary items include rodents, plants, birds and reptiles and livestock (Henschel and Skinner 1990; Holmern et al. 2007). Considering its high behavioural plasticity including frequent opportunistic scavenging (Holekamp and Dloniak 2010), it is not surprising that this species often exploits anthropogenic food (Mills and Hofer 1998). Whilst scavenging anthropogenic food has previously been reported anecdotally (Henschel 1986; Mills and Hofer 1998), it is only in more recent years that this has become the focus of scientific inquiry (Ryan 2007; Kolowski and Holekamp 2008; Fourie 2008; Abay et al. 2010; Belton 2017). As with other species, a diet switch based on availability of anthropogenic food has been recorded (Yirga et al. 2012), and access to anthropogenic food has also been related to other aspects of spotted hyaena behavioural ecology (Kolowski and Holekamp 2008; Belton et al. 2016, Belton et al. 2018).

In this study, we investigated the effects of human habitation and of anthropogenic resources on spotted hyaena diet in one of the largest protected areas in southern Africa, the Kruger National Park (KNP). KNP is open to the public, attracts over one million visitors per year, and has numerous facilities for tourists along with staff accommodation that vary in size (SANParks 2011). The KNP is home to an approximately 5000 spotted hyaenas (Ferreira and Funston 2016). We predicted that the size of sites of human habitation would be positively related to the amount of available anthropogenic food, and subsequently that spotted hyaenas close to large sites would utilise more anthropogenic food compared to spotted hyaenas close to small ones. Finally, spotted hyaena diet is seasonally variable, and seasonal variation in native food has been associated with more frequent anthropogenic food use (Kolowski \& Holekamp, 2008; Yirga et al. 2012). In the KNP, seasonal rainfall drives a pulse in ungulate births during the early wet season (Owen-Smith and Ogutu 2013). We predicted that this would generate a seasonal variation in prey abundance, which would be reflected in a seasonal variation of the utilization of anthropogenic food.

\section{Materials and methods}

Study area

KNP is situated in the North Eastern corner of South Africa (31 $\left.37^{\prime} 38.513^{\prime \prime} E, 2^{\circ} 10^{\prime} 18.804^{\prime \prime S}\right)$ and covers $19485 \mathrm{~km}^{2}$. Our study focused on the southern section of the KNP, which covers $5000 \mathrm{~km}^{2}$ (Fig. 1). Vegetation in this area of the park is characterised by woodland. Basalt soils are dominated by Sclerocarya caffra and Acacia nigrescens, with Combretum species on granite soils (Ogutu and Owen-Smith 2003). Rainfall is seasonal with the majority falling between October and March, with a peak in January and February (Venter et al. 2003). Average annual rainfall is approximately 650 $\mathrm{mm}$ for the Southern section (Venter and Gertenbach 1986). Mean monthly temperatures range from 7 to $32^{\circ} \mathrm{C}$ for this area (Venter and Gertenbach 1986). KNP hosts a diverse array of herbivorous and carnivorous mammals. Large and small ungulates in the Southern section of the park include: impala (Aepyceros melampus), blue wildebeest (Connochaetes taurinus), zebra (Equus quagga), kudu (Tragelaphus strepsiceros), warthog (Phacochoerus aethiopicus), bushbuck (Tragelaphus sylvaticus), nyala (Tragelaphus angasii), common reedbuck (Redunca arundinum), waterbuck (Kobus ellipsiprymnus), steenbok (Raphicerus campestris), common duiker (Sylvicapra grimmia) and Cape buffalo (Syncerus caffer). Other megaherbivores including elephant (Loxodonta africana), white rhinoceros (Ceratotherium simum), black rhinoceros (Diceros bicornis), and giraffe (Giraffa camelopardalis) are also available as prey for large predators, but are presumably most often 
utilized as carrion. Impala constitutes large a part of the spotted hyaena diet in KNP (Henschel and Skinner 1990; Ryan 2007). Four large carnivores live sympatrically with spotted hyaenas in KNP: African lion (Panthera leo), leopard (Panthera pardus), cheetah (Acinonyx jubatus), and African wild dog (Lycaon pictus) (Owen-Smith and Mills 2008).

\section{Defining anthropogenic sites}

Within KNP there are amenities for visitors in the form of rest camps and picnic sites. We used 8 fixed sites of elevated human activity to evaluate anthropogenic effects on spotted hyaena diet (Fig 1). Throughout the manuscript, we will use the collective term 'anthropogenic sites' for these locations. Since we did not posses direct data on the amount of activity in each site, we used their spatial extent as a proxy for the amount of human activity and infrastructure they harboured. We used satellite images from Google Earth (http://earth.google.com/) to create polygons that outlined each anthropogenic site, and used these polygons to quantify the area of each site in $\mathrm{km}^{2}$. The sizes of these varied from $1.6 \mathrm{~km}^{2}$ of human infrastructure in Skukuza to $0.001 \mathrm{~km}^{2}$ in Mlondozi (Table 1). Skukuza, Bergendal, Pretoriuskop, Lower Sabie and Crocodile bridge are rest camps, which consisted of fenced areas used for guests staying overnight in the park along with associated staff accommodation and administrative buildings. Afsaal, Nkhulu and Mlondozi are picnic sites, where unfenced areas with a shop used by visitors during visitors during daylight hours. Skukuza is the largest rest camp in KNP and is the administrative centre of the park. Skukuza is the only site that contains both a picnic site and a rest camp. However, due to the size of this site and its associated infrastructure the picnic site was regarded as part of the Skukuza complex. Smaller private rest camps exist but were not included in the study due to their small size and limited access to the roads surrounding them.

Since spotted hyaenas are highly mobile animals, the locations where scats were located and picked up may not be directly relevant to where the spotted hyaenas were at the time the food contained in the scat was ingested. To provide a spatial evaluation of the importance of access to anthropogenic sites on spotted hyaena diet, we therefore created buffer zones around each site which approximated the size of recorded annual spotted hyaena home ranges within the southern section of the park (Belton et al. 2016). Hence, food items found in scats located inside these areas were more likely to have been ingested close to anthropogenic sites than scats located outside these areas. We calculated these buffer zones by first estimating the geographic centre of the polygon of each site, and then creating a circular buffer around this centre with a radius of $4 \mathrm{~km}$, which generates a circular area of $50.27 \mathrm{~km}^{2}$, corresponding to the mean estimated annual home range sizes for spotted hyaenas in the southern section of the KNP during the study period (Belton et al. 2016).

\section{Litter survey}

We further used the amount of roadside litter as a crude proxy for spatial variation in the intensity of human activity, and made the ad-hoc assumption that intensity of human activity on a broad spatial scale is related to the amount of available anthropogenic resources. During the 2010 wet season, we recorded litter on the road sides whilst carrying out scat collection (Fig. 1). We recorded all litter within one metre of the edges of the road for all the roads covered in the scat collection. Litter was classed as paper, plastic, metal, glass, and miscellaneous, containing organic material such as discarded food and fabric, and for each observation a spatial coordinate was taken. We quantified litter intensity as number of occurrences per $1 \mathrm{~km}$ of road by splitting all roads into $1 \mathrm{~km}$ segments and counting the number of litter occurrences within each segment. For the centre point of each segment we identified the nearest anthropogenic site as well as the distance to the centre of this site, and each observation of litter was coded as occurring inside or outside the buffer zone for that site. 
We stress that this survey should not be regarded as a quantitative survey of anthropogenic material available to spotted hyaenas, but it does provide a qualitative evaluation of the spatial variation in the intensity of human activity (Belton et al. 2018).

Scat collection and diet estimation

Scat samples were collected from August to September 2009 (dry season) and during the beginning of April 2010 (end of the wet season). Scats were opportunistically located while slowly driving public as well as the private roads (Fig. 1). While driving, two observers scanned the roadsides for samples. Spotted hyaena scats were identified by their white colouring, their size, and the tendency of the animals to make use of latrines. Samples were put into paper bags, and stored in a cool dry place until further analysis. Spotted hyaena scats are typically comprised of animal matter, for example bone shards and hair, some plant matter and faecal matrix (Henschel and Skinner 1990; Fourie 2008). To remove as much faecal matrix as possible, samples were crushed in a pestle with a mortar, sewn into individual cloth bags, soaked overnight and then put through two cold wash cycles of a washing machine. Samples were then sieved, before being dried for 48 hours in an oven at $55^{\circ} \mathrm{C}$.

For each scat, we identified the nearest anthropogenic site, and coded the location of the scat as being inside or outside of the buffer zone of that site (Fig. 1). For each season we randomly selected 308 washed samples, 154 for each category (i.e. inside or outside of buffer zones, Table 1), for further diet analyses. Each of these samples were, once dried, spread out on a sheet of white paper and diet components were recorded into four broad categories; mammal, anthropogenic material, plant and miscellaneous (including 118 occurrences of invertebrate remains, 8 occurrences of reptile remains, and 2 occurrences of bird remains). We excluded faecal matrix as a diet category, but it occurred in $92.8 \%$ of the washed samples. For anthropogenic material, we also recorded the type of material, e.g. plastic, paper or metal. Since volumes of particular items in scats do not accurately depict the amount of each item consumed (Henschel and Skinner 1990), we present diet content as frequency of occurrence, which for overall diet has been expressed as the proportion of total number of analyzed scats per site and for different types of anthropogenic material as proportion of scats containing anthropogenic material per site.

\section{Data analyses}

We used generalised linear mixed models to evaluate the effect of distance to nearest anthropogenic site and season on litter abundance, type of litter found, diet composition, proportion of anthropogenic material in scats and the relative composition of types of anthropogenic material found in scats. We used a Poisson error distribution and a log link function in the model evaluating the effects of size and the distance to the nearest anthropogenic site on the abundance of road side litter. This model had the observed litter counts per segment of road as the response variable, distance to nearest anthropogenic site from the centre of the segment, size of the nearest anthropogenic site and the two-way interaction as fixed effects. Because not all road segments were exactly $1 \mathrm{~km}$ in length, we used segment length as an offset, so that we quantified the effects on amount of litter per distance of road. We log transformed distance to the nearest anthropogenic site before entering it into the model. All other models were fitted using binomial errors and logit links, and contained season, the distance to (quantified as inside or outside of buffer zones) and the size of the nearest anthropogenic site as fixed effects. The models on relative composition of the categories of litter, diet composition and the composition of anthopogenic material found in scats also contained litter category, diet category or category of anthropogenic material, respectively. We also added all interaction terms into the fixed effect structure. For these models, we used the proportion 
of each litter category, of each diet item, of scats that contained anthropogenic material or of the category of anthropogenic material as response variables. For all models, we fitted the identity of the nearest anthropogenic site as a random term to account for inherent differences between each of the locations. We evaluated fixed effects by sequentially removing them in order of complexity using likelihood ratio tests (Crawley 2007), analogously to type II sums of square tests (e.g. Hector et al. 2010). We used planned comparisons using least square means to compare the frequency of occurrence between wet and dry season for each diet category (Lenth 2016). We adjusted the pvalues for these contrasts using the false discovery rate method (Benjamini and Hochberg 1995). Data was analysed with the statistical package R 3.3.2 (http://www.r-project.org) using the lme4 (Bates et al. 2011) and lsemans (Lenth 2016) packages.

\section{Results}

\section{Litter Density}

We surveyed $884 \mathrm{~km}$ of roads and recorded 1649 individual pieces of litter, although $50.3 \%$ of the road sections were litter free. There was a significant interaction effect of the size of, and distance to, the nearest anthropogenic site on litter abundance, with a faster decline in litter abundance with increasing distances from larger sites than from smaller ones $\left(\beta=-0.02, \mathrm{SE}_{\beta}=0.003, Z=6.70, P<\right.$ $0.01)$. This larger effect of distance around bigger sites was caused by a higher amount of litters close to large sites (Fig. 2a). Both distance to $\left(\chi^{2}=14.72, d f=4, P<0.01\right.$ ) and size of the nearest anthropogenic site $\left(\chi^{2}=17.96, d f=4, P<0.01\right)$ influenced the type of litter observed, but distance and size did not interact in their effects $\left(\chi^{2}=4.38, d f=4, P=0.36\right)$. The most abundant forms of litter observed were plastic and paper, with plastic being more abundant close to sites and paper further away from sites (Fig. 2b). Organic material (i.e. discarded food) contributed little (0.9\%) to the total amount of litter observed.

\section{Overall diet content}

There was a significant two-way interaction between diet category and season on spotted hyaena diet composition $\left(\chi^{2}=11.15, d f=4, P=0.02\right)$, but no three way interaction between diet category, season and distance to anthropogenic sites (i.e. inside or outside buffers) $\left(\chi^{2}=5.13, d f=4, P=\right.$ $0.27)$ or two way interactions between diet category and distance to anthropogenic site $\left(\chi^{2}=0.71, d f\right.$ $=4, P=0.95$ ) (Fig. 3a). The size of the nearest anthropogenic site did not have a significant influence on the interaction between diet category, season and distance to nearest anthropogenic site $\left(\chi^{2}=1.24, d f=4, P=0.87\right)$, the interaction between diet category and season $\left(\chi^{2}=2.91, d f=4, P=\right.$ $0.57)$ or the interaction between diet category and distance to the nearest anthropogenic site $\left(\chi^{2}=\right.$ $0.46, d f=4, P=0.98)$. There was similarly no significant interaction effect of the size of the nearest anthropogenic site and diet category $\left(\chi^{2}=4.04, d f=4, P=0.40\right)$.

There was a significantly higher proportion of scats containing plants in the dry than in the wet season $\left(\beta=-0.34, S E_{\beta}=0.14, Z=2.49, P_{a d j}=0.03\right)$, but a lower proportion of scats containig items of the miscellaneous category in the dry season $\left(\beta=0.81, S E_{\beta}=0.29, Z=2.81, P_{a d j}=0.02\right)$. There were no significant seasonal differences for either mammals $\left(\beta=-0.05, S E_{\beta}=0.12, Z=0.48, P_{a d j}=\right.$ $0.63)$ or anthropogenic resources $\left(\beta=-0.47, S E_{\beta}=0.27, Z=1.74, P_{a d j}=0.11\right)$.

\section{Anthropogenic content of scats}

The presence of anthropogenic material in scats was low, and occurred in only $12.3 \%$ and $5.8 \%$ of the scats found close to anthropogenic sites in the dry and wet season, respectively, and in $19.1 \%$ and $8.2 \%$ of the scats found far from anthropogenic sites in the dry and wet season (Fig 3a). Overall, anthropogenic material was found in $10.6 \%$ of the analyzed scats. There were no 
significant effects of neither distance to anthropogenic site $\left(\chi^{2}=0.18, d f=1, P=0.67\right)$, season $\left(\chi^{2}=\right.$ 2.39, $d f=1, P=0.12)$ nor an interaction between distance and season $\left(\chi^{2}=0.91, d f=1, P=0.34\right)$. The size of the anthropogenic site did not either influence the proportion of scats with anthropogenic material $\left(\chi^{2}=0.56, d f=1, P=0.45\right)$,

Plastic was the most commonly found type of anthropogenic material (Fig 3b), found in $77.0 \%$ of scats that contained anthropogenic material. There were no significant three way interaction effect of type of material, season and distance to anthropogenic site on the frequency of the different materials $\left(\chi^{2}=0.25, d f=2, P=0.88\right)$, or significant two way interactions between either type of material and season $\left(\chi^{2}=2.94, d f=2, P=0.23\right)$ or type of material and distance to anthropogenic site $\left(\chi^{2}=0.65, d f=1, P=0.72\right)$. The size of the nearest anthropogenic site did not affect the three way interaction of type of material, season and distance to anthropogenic site $\left(\chi^{2}<0.01, d f=1, P=\right.$ $0.99)$, or the two way interactions of type of material and season $\left(\chi^{2}=1.49, d f=1, P=0.22\right)$ and type of material and distance to anthropogenic site $\left(\chi^{2}=0.01, d f=1, P=0.93\right)$. There was similarly no interaction of size of the nearest anthropogenic site and type of anthropogenic material $\left(\chi^{2}=\right.$ $1.59, d f=1, P=0.21)$.

\section{Discussion}

Overall diet content concurred with other studies on spotted hyaenas, with the most common component being mammals, but also to lesser extent reptilian and invertebrate remains (Henschel and Skinner 1990). The amount of anthropogenic material in scats was low, occurring in only $11 \%$ of the analyzed scats. We found no effect of the distance to, or the size of, the distance to or the size of the nearest anthropogenic site on the proportion of scats that contained anthropogenic material, despite observations of more litter in close vicinity to large anthropogenic sites. This suggests anthropogenic resources and infrastructure had little effect on spotted hyaena diet in the KNP. Previous studies on other carnivore species have consistently found a higher use of anthropogenic resources in areas with high levels of human habitation (Fedriani et al. 2001; Newsome et al. 2010; Grigione et al. 2011).

In our study, spotted hyaena scats collected within one home range radius from anthropogenic sites were not more likely to contain anthropogenic material than scats collected outside of this zone. In addition, we found no effect of the size of anthropogenic sites on the probability of finding anthropogenic material in scats. Considering that both size and distance influenced the frequency of anthropogenic material found along roads, these results suggest that spotted hyaenas in the southern section of the KNP do not appear to feed on anthropogenic food in relation to its abundance. This implies that use of anthropogenic food is not opportunistic. However, we appreciate that garbage sites may have influenced the availability of anthropogenic food more than what our survey of roadside litter detected. Instead, these results suggest that anthropogenic food was used either by certain individuals within the population, or that it was used opportunistically by a sub-set of the population, which may have diluted any effects of litter abundance on the frequency of anthropogenic materials in scats. Such individuals are likely to have been low ranking animals or recently dispersed males, since these individuals often have limited access to carrion and kill sites (Frank 1986).

Although we found a seasonal difference in diet composition, the differences appeared to have been caused primarily by occasionally utilized prey or accidentally ingested items such as plants. We found no seasonal differences in the proportion of scats that contained anthropogenic material, or in 
the types of anthropogenic material found in scats. Our results therefore contradict observations of seasonal variation in the utilization of anthropogenic resources in coyotes, Arctic foxes, red foxes and brown bears (Morey et al. 2007; Savory et al. 2014; Kavčič et al. 2015), as well as in spotted hyaenas in east Africa (Kolowski and Holekamp 2008). However, we highlight that seasonal variation among the main prey, i.e. medium sized and large mammals, could have occurred. The rainfall received during the wet season is associated with an increased abundance of young animals (Owen-Smith and Ogutu 2013), which spotted hyaenas preferentially prey on (Kruuk 1972; OwenSmith and Mills 2008). Our broad pooling of diet categories could therefore have prevented us from detecting seasonal effects on predation on certain age classes or prey switches among different ungulate species.

We highlight several shortcomings with our study. First, our litter survey only provided a crude proxy for available anthropogenic resources, and only during one season. A more comprehensive and direct mapping of spatial and temporal variation in anthropogenic resources may be highly informative, especially to evaluate over what spatial and temporal scales anthropogenic resources may be important within this protected area. Second, we used a crude classification of spotted hyaena diet. Although we did this deliberately to focus on the anthropogenic content in the diet, it could have muted indirect effects of anthropogenic activities and infrastructure for instance related to shifts in prey selection within our broad mammal class. Finally, we note that our findings are a conservative estimate of anthropogenic food use in KNP. Anthropogenic material in scats may not accurately reflect the amount of anthropogenic food consumed since digestible foods, such as processed carbohydrates and meat, are not quantifiable through scat analysis (eg., observations in the San Joaquin kit fox Vulpes macrotis mutica, Newsome et al. 2010). For a full evaluation of the importance of anthropogenic material, it may be useful to evaluate stable isotope markers and to directly conduct behavioural observations around likely resource hubs such as garbage sites. However, despite the potential effects of localised resources, we argue that our survey covered a large section of the southern KNP, and hence that our results are robust in that anthropogenic resources likely are not important across broader spatial scales. However, they may be used locally or by specific individuals (Belton 2017).

In conclusion, our study suggested no direct effect of anthropogenic resources on spotted hyaena diet in the KNP. We found neither temporal nor spatial variation in either the amount of, or types of, anthropogenic material in spotted hyaena scats. We detected a substantial spatial variation in the amount of road side litter. Providing that this litter is a reasonably good proxy for spatial variation in anthropogenic resources, anthropogenic resources may be preferentially used by specific individuals or opportunistically used by a subset of the individuals within the population. We suggest that further research may be useful to evaluate potential secondary effects of human infrastructure on spotted hyaena prey utilization, and also that an extended study utilizing stable isotope analyses may provide insights that may not have been gained by our analyses of scat content.

\section{Acknowledgements}

We are grateful for the support of South African National Parks and the staff of Kruger National Park for their assistance with this study. Mariana Venter and Daniël Swanepoel kindly assisted in the field. Funding was provided by the National Research Foundation (incentive funding for rated researchers to EZC and FD), and by the University of Pretoria. Research was approved by the University of Pretoria Animal Use and Care Committee (protocol number EC010-07) and the Kruger National Park Animal Use and Care Committee. 
Diet of spotted hyaenas

\section{References}

Abay GY, Bauer H, Gebrihiwot K, Deckers J (2010) Peri-urban spotted hyena (Crocuta crocuta) in Northern Ethiopia: diet, economic impact, and abundance. Eur J Wildl Res 57:759-765

Bateman PW, Fleming PA (2012). Big city life: carnivores in urban environments. J Zool 287:1-23

Bates D, Maechler M, Bolker B (2011) lme4: Linear mixed-effects models using S4 classes. R package version 0.999375-39. http://CRAN.R-project.org/package=lme4.

Beckmann JP, Berger J (2003) Rapid ecological and behavioural changes in carnivores: the responses of black bears (Ursus americanus) to altered food. J Zool 261:207-212

Benjamini Y, Hochberg Y (1995). Controlling the false discovery rate: a practical and powerful approach to multiple hypothesis testing. J Roy Stat Soc B 57: 289-300

Belton L (2017) Anthropogenic influences on spotted hyaenas in a protected area, the Kruger National Park. PhD thesis, University of Pretoria, Pretoria

Belton L, Cameron EZ, Dalerum F (2016) Spotted hyaena space use in relation to human infrastructure inside a protected area. PeerJ 4:e2596

Belton L, Cameron EZ, Dalerum F (2018) Social networks of spotted hyaenas in areas of contrasting human activity and infrastructure. Anim Behav 135:13-23

Cooper SM, Holekamp KE, Smale L (1999) A seasonal feast: long-term analysis of feeding behaviour in the spotted hyaena (Crocuta crocuta). Afr J Ecol 37:149-160

Crawley MJ (2007) The R book. John Wiley \& Sons, Chichester

Fedriani JM, Fuller TK, Sauvajot RM (2001) Does availability of anthropogenic food enhance densities of omnivorous mammals? An example with coyotes in southern California. Ecography $24: 325-331$

Ferreira SM, Funston PJ (2016) Population estimates of spotted hyaenas in the Kruger National Park, S Afr J Wildl Res 46:61-70.

Fourie C (2008) The influence of seasons and human density on anthropogenic food consumption in the spotted hyaena Crocuta crocuta in Kruger National Park. Honours Thesis, University of Pretoria South Africa.

Frank LG (1986) Social organization of the spotted hyaena Crocuta crocuta. II. Dominance and reproduction. Anim Behav 34:1510-1527

Gilchrist JS, Otali E (2002) The effects of refuse-feeding on home-range use, group size, and intergroup encounters in the banded mongoose. Can J Zool 80:1795-1802

Grigione MM, Burman P, Clavio S, Harper SJ, Manning D, Sarno RJ (2011) Diet of Florida coyotes in a protected wildland and suburban habitat. Urb Ecosyst 14:655-663

Hayward MW (2006) Prey preferences of the spotted hyaena (Crocuta crocuta) and degree of 
Diet of spotted hyaenas

dietary overlap with the lion (Panthera leo) J Zool 270:606-614

Hector A, von Felten S, Schmid B (2010) Analysis of variance with unbalanced data: an update for ecology \& evolution. J Anim Ecol 79:308-316

Henschel JR (1986) The socio-ecology of a spotted hyaena (Crocuta crocuta) clan in the Kruger National Park. Dissertation, University of Pretoria.

Henschel JR, Skinner JD (1990) The diet of the spotted hyaenas Crocuta crocuta in Kruger National Park. Afr J Ecol 28:69-82

Holekamp KE, Dloniak SM (2010) Intraspecific variation in the behavioral ecology of a tropical carnivore, the spotted hyaena. Adv Stud Behav 42:189-229

Holmern T, Nyahongo J, Røskaft E (2007) Livestock loss caused by predators outside the Serengeti National Park, Tanzania. Biol Cons 135:518-526

IUCN (2015) The IUCN Red List of Threatened Species. Version 2015.1.

$<\mathrm{http}: / /$ www.iucnredlist.org $>$. Downloaded on 22nd June 2015.

Kavčič I, Adamič M, Kaczensky P, Krofel M, Kobal M, Jerina K (2015) Fast food bears: brown bear diet in a human-dominated landscape with intensive supplemental feeding. Wildl Biol 21:1-8

Kolowski JM, Holekamp KE (2008) Effects of an open refuse pit on space use patterns of spotted hyenas. Afr J Ecol 46:341-349

Kruuk H (1972) The spotted hyena: a study of predation and social behavior. University of Chicago, Chicago.

Laver PN (2013) The foraging ecology of banded mongooses (Mungos mungo): Epidemiological and human-wildlife conflict implications. Virginia Polytechnic Institute and State University Blacksburg, Virginia. Available at: http://vtechworks.lib.vt.edu/handle/10919/50973 [Verified 18 April 2015]

Lenth RV (2016). Least-squares means: The R Package lsmeans. J Stat Softw 69: 1-33.

Lukasik V, Alexander S (2012) Spatial and temporal variation of coyote (Canis latrans) diet in Calgary, Alberta. Cities and the environment (CATE) 4. Available at:

http://digitalcommons.lmu.edu/cate/vol4/iss1/8

Magle SB, Hunt VM, Vernon M, Crooks, KR (2012) Urban wildlife research: Past, present, and future. Biol Cons 155:23-32

Mills MGL (1984) The comparative behavioural ecology of the brown hyaena Hyeana brunnea and the spotted hyaena Crocuta crocuta in the southern Kalahari. Koedoe 27:237-247

Mills MGL, Hofer H (1998) Hyaenas. Status survey and conservation action plan. Gland, IUCN

Morey PS, Gese EM, Gehrt S (2007) Spatial and temporal variation in the diet of coyotes in the Chicago Metropolitan Area. Am Midl Nat 158:147-161 


\section{Diet of spotted hyaenas}

Murray M, Edwards MA, Abercrombie B, Clair CCS (2015) Poor health is associated with use of anthropogenic resources in an urban carnivore. Proc Roy Soc B 282:20150009

Newsome SD, Garbe HM, Wilson EC, Gehrt SD (2015) Individual variation in anthropogenic resource use in an urban carnivore. Oecologia 178:115-128

Newsome SD, Ralls K, Job CVH, Fogel ML, Cypher BL (2010) Stable isotopes evaluate exploitation of anthropogenic foods by the endangered San Joaquin kit fox (Vulpes macrotis mutica). J Mamm 91:1313-1321

Ogutu JO, Owen-Smith N (2003) ENSO, rainfall and temperature influences on extreme population declines among African savanna ungulates. Ecol Lett 6:412-419

Owen-Smith N, Mills MGL (2008) Predator-prey size relationships in an African large-mammal food web. J Anim Ecol 77:173-183

Owen-Smith N, Oguto OJ (2013) Controls over reproductive phenology among ungulates: allometry and tropical-temperate contrasts. Ecography 36:256-263

Quinn JH, Whisson DA (2005) The effects of anthropogenic food on the spatial behaviour of small Indian mongooses (Herpestes javanicus) in a subtropical rainforest. J Zool 267:339-350

Ryan B (2007) Effects of anthropogenic food sources on diet and parasite loads in spotted hyaena, Crocuta crocuta (Erxleben, 1777) in Kruger National Park. Dissertation, University of Pretoria South Africa

Š́álek M, Drahníková L, Tkadlec E (2015) Changes in home range sizes and population densities of carnivore species along the natural to urban habitat gradient. Mammal Review 45:1-14

SANParks (2011) South African National Parks Annual Report 2010/11. Available at: http://www.sanparks.co.za/assets/docs/general/annual-report-2011.pdf

Savory GA, Hunter CM, Wooller MJ, O’Brien DM (2014) Anthropogenic food use and diet overlap between red foxes (Vulpes vulpes) and arctic foxes (Vulpes lagopus) in Prudhoe Bay, Alaska. Can J Zool 92:657-663

Trinkel M (2009) Prey selection and prey preferences of spotted hyenas Crocuta crocuta in the Etosha National Park, Namibia. Ecol Res 25:413-417

Venter FJ, Gertenbach WPD (1986) A cursory review of the climate and vegetation of the Kruger National Park. Koedoe 29:139-148

Venter FJ, Scholes RJ, Eckhardt HC (2003) The abiotic template and its associated vegetation patterns. In: Du Toit JT, Rogers KH, Biggs HC (eds) The Kruger experience: ecology and management of savanna heterogeneity'. Island Press, Washington DC, pp. 83-129

Widdows CD, Downs CT (2015) A genet drive-through: are large spotted genets using urban areas for 'fast food'? a dietary analysis. Urb Ecosyst 18:907-920

Woodroffe R (2000) Predators and people: using human densities to interpret declines of large 
Diet of spotted hyaenas

carnivores. Anim Cons 3:165-173

Yirga G., De Iongh HH, Leirs H, Gebrihiwot K, Deckers J, Bauer H (2012) Adaptability of large carnivores to changing anthropogenic food sources: diet change of spotted hyena (Crocuta crocuta) during Christian fasting period in northern Ethiopia. J Anim Ecol 81:1052-1055 


\section{Diet of spotted hyaenas}

Table 1 Types and sizes in approximate area of built up area of 8 anthropogenic sites, as well as the amount of roads monitored for litter and scats and number of analyzed scats collected inside and outside $50 \mathrm{~km}^{2}$ buffer zones surrounding each area.

\begin{tabular}{|c|c|c|c|c|c|c|c|c|}
\hline \multirow[b]{3}{*}{ Site } & \multirow[b]{3}{*}{ Type of site } & \multirow[b]{3}{*}{ Size $\left(\mathrm{km}^{2}\right)$} & \multicolumn{2}{|c|}{ Roads monitored (km) } & \multicolumn{4}{|c|}{ Number of analyzed scats } \\
\hline & & & \multirow[b]{2}{*}{ In } & \multirow[b]{2}{*}{ Out } & \multicolumn{2}{|c|}{ Dry season } & \multicolumn{2}{|c|}{ Wet season } \\
\hline & & & & & In & Out & In & Out \\
\hline Skukuza & Rest camp & 1.624 & 49.8 & 127.5 & 63 & 57 & 38 & 23 \\
\hline Bergendal & Rest camp & 0.283 & 14.8 & 46.5 & 9 & 1 & 14 & 0 \\
\hline Pretoriouskop & Rest camp & 0.185 & 44.1 & 97.9 & 3 & 18 & 3 & 18 \\
\hline Lowe Sabie & Rest camp & 0.183 & 27.0 & 72.7 & 19 & 4 & 28 & 13 \\
\hline Crocodile bridge & Rest camp & 0.079 & 14.2 & 77.8 & 16 & 18 & 17 & 39 \\
\hline Afsaal & Picnic site & 0.008 & 19.2 & 141.2 & 9 & 31 & 8 & 18 \\
\hline Nkuhlu & Picnic site & 0.005 & 16.0 & 60.0 & 21 & 17 & 34 & 33 \\
\hline Mlondozi & Picnic site & 0.001 & 24.1 & 50.9 & 14 & 8 & 12 & 10 \\
\hline
\end{tabular}




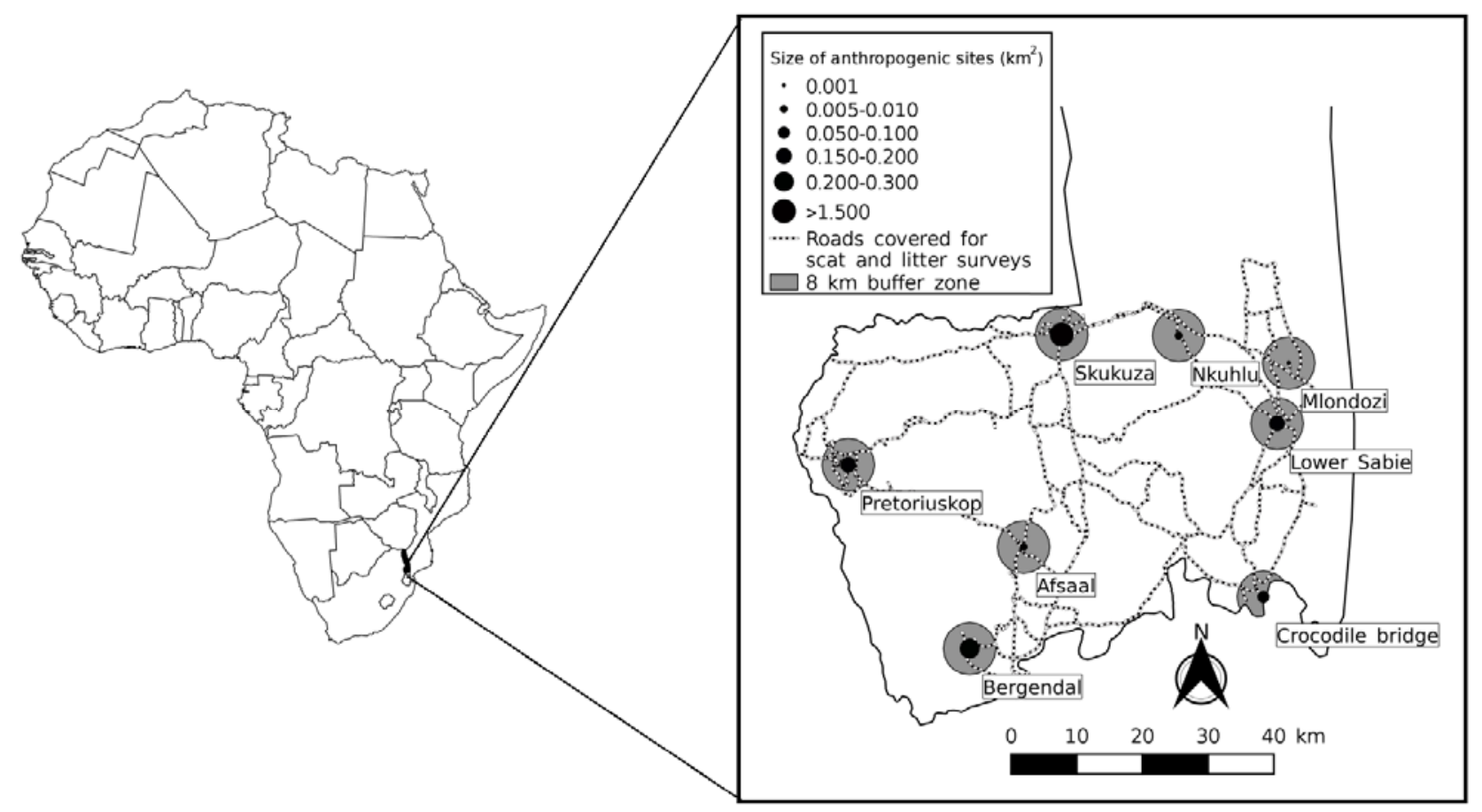

Fig. 1: The southern section of the Kruger National Park within South Africa, including the anthropogenic sites and associated $50 \mathrm{~km}^{2}$ buffer zones, which approximates the size of a spotted hyaena clans home range buffers, , as well as roads surveyed for spotted hyaena scats and litter. 
Diet of spotted hyaenas
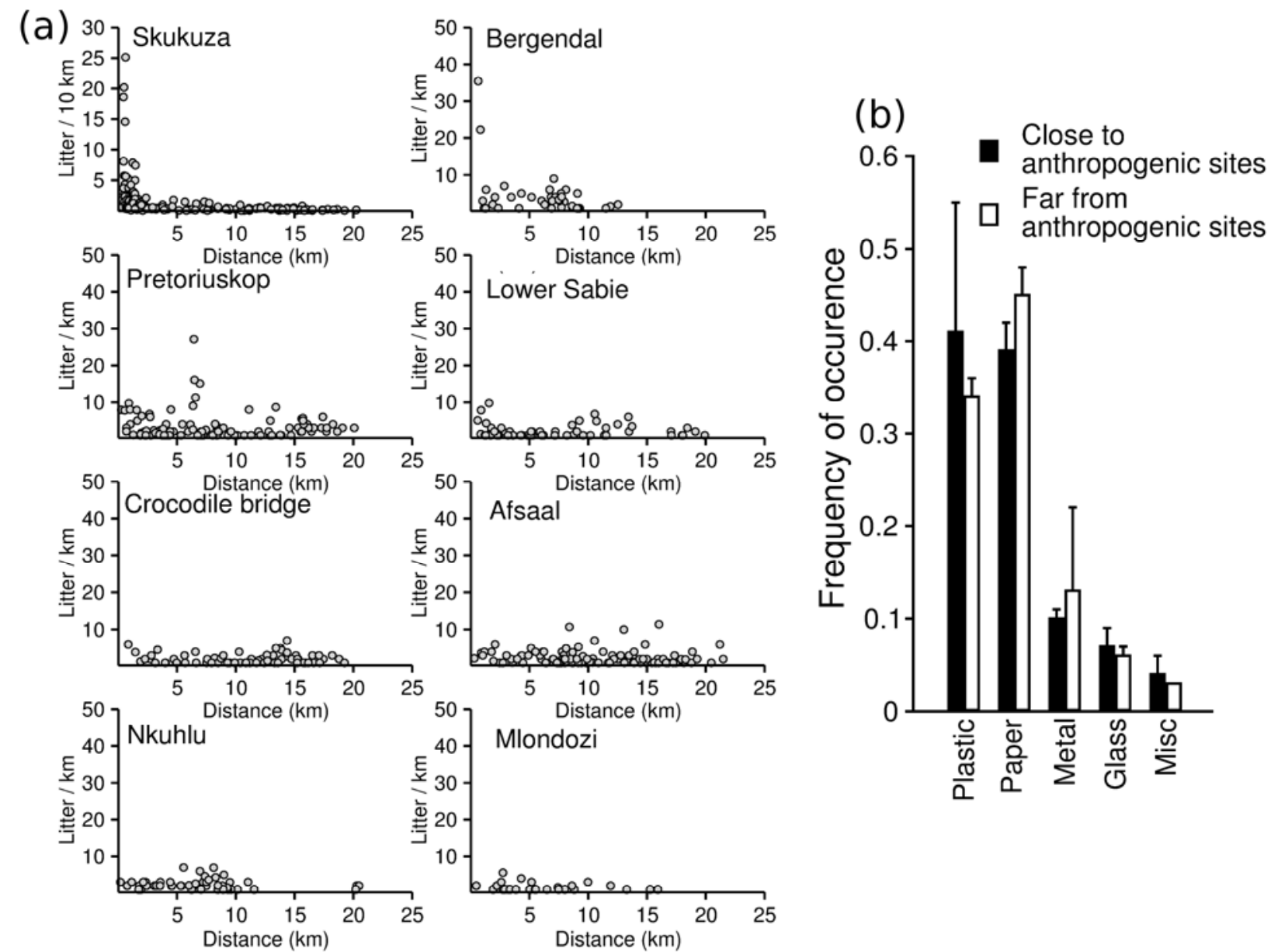

Fig. 2: The relationship between the frequency of roadside litter and distance to the nearest anthropogenic sites for 8 sites of different sizes (Skukuza $1.62 \mathrm{~km}^{2}$, Bergendal $0.28 \mathrm{~km}^{2}$, Pretoriuskop $0.18 \mathrm{~km}^{2}$, Lower Sabie $0.18 \mathrm{~km}^{2}$, Crocodile bridge $0.08 \mathrm{~km}^{2}$, Afsaal $0.01 \mathrm{~km}^{2}$, Nkuhlu $0.005 \mathrm{~km}^{2}$, and Mlondozi $0.001 \mathrm{~km}^{2}$ ) in the southern Kruger National Park (a) and the frequency of occurrences of different types of litter within and outside $50 \mathrm{~km}^{2}$ buffer zones, which approximates the area of a spotted hyaena clans home range (b). 
Diet of spotted hyaenas
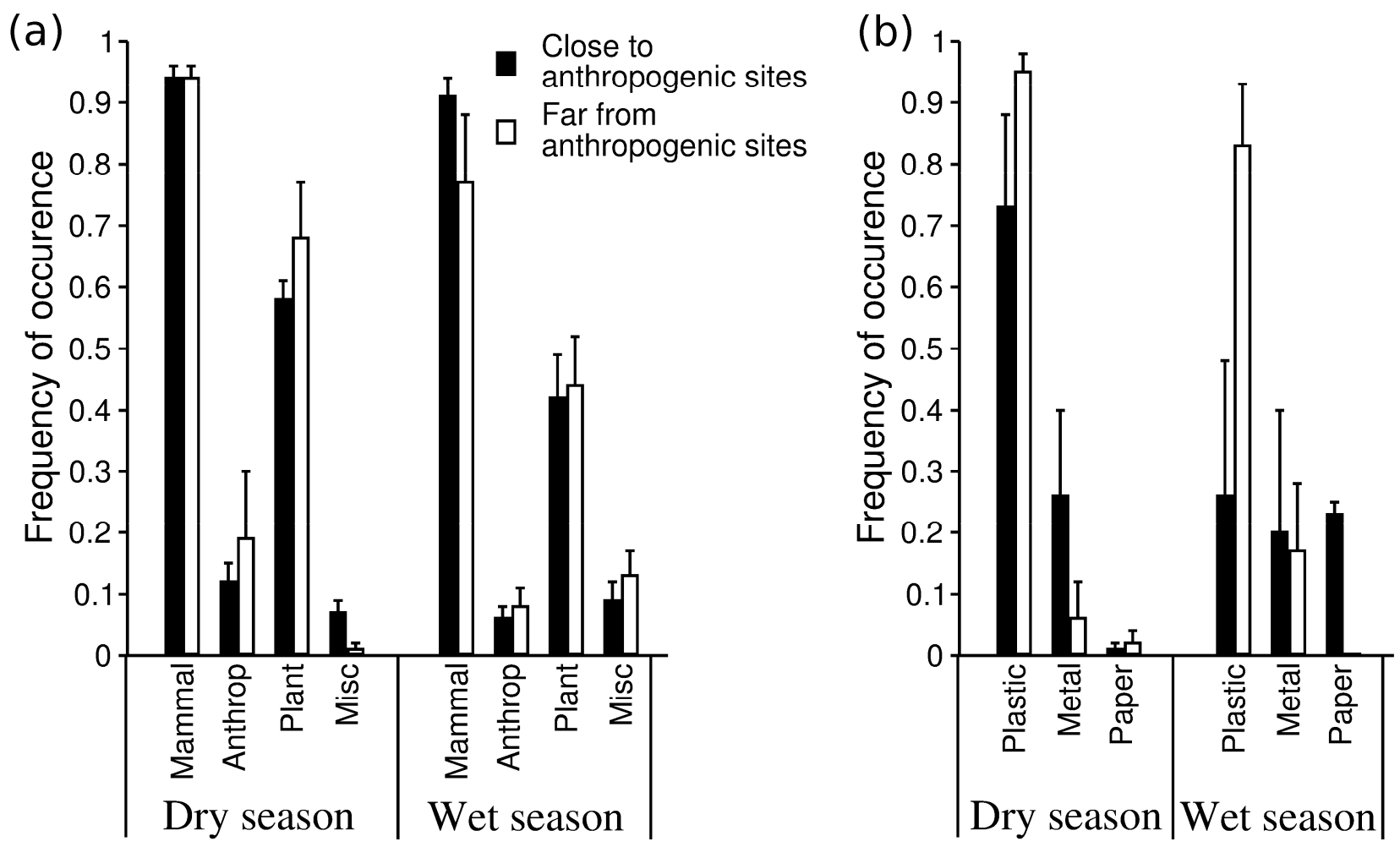

Fig. 3: Diet composition estimated as frequency of occurrence (i.e. proportions of scats containing each prey items) of four major diet categories (a) and frequency of occurrence (proportion of scats containing anthropogenic material) of three types of anthropogenic materials (b) estimated from scats collected close to and from anthropogenic sites, quantified as whether or not a scat was collected inside (close) or outside (far) of 1 home range diameter wide buffer zones around the centre of anthropogenic sites. The bars provide mean $\pm 1 \mathrm{SE}$ of the different anthropogenic sites. 